\title{
Multi-proxy reconstruction of marine inorganic carbon chemistry in the Benguela Upwelling System during the last 25 ka
}

\author{
SZABINA KARANCZ ${ }^{1}$, LENNART J DE NOOIJER ${ }^{2}$, RICK \\ HENNEKAM $^{2}$, ZEYNEP ERDEM ${ }^{2}$, NEGAR HAGHIPOUR ${ }^{3}$, \\ STEFAN SCHOUTEN $^{2,4}$, BAS VAN DER WAGT ${ }^{2}$ AND \\ GERT-JAN REICHART ${ }^{2,4}$
}

${ }^{1}$ NIOZ-Royal Netherlands Institute for Sea Research

${ }^{2}$ NIOZ-Royal Netherlands Institute for Sea Research

${ }^{3}$ ETH Zurich

${ }^{4}$ Utrecht University

Presenting Author: szabina.karancz@nioz.nl

Studies on upwelling intensity during the last glacial cycle in the Benguela Upwelling System offshore Namibia show contrasting signals, indicating an incomplete understanding of regional changes. We investigate the evolution of the inorganic carbon chemistry during the last deglaciation in a sediment core from the Walvis Ridge to improve our understanding of upwelling and its association to $\mathrm{CO}_{2}$ outgassing. Cold waters brought to the surface from depth has high dissolved inorganic carbon (DIC) content, which causes an initial increase in $p \mathrm{CO}_{2}$ and a decrease in $\mathrm{pH}$ and carbonate saturation at the sea surface. Concurrently, the nutrient supply of the upwelled waters and the efficiency of the biological carbon pump provide an important constraint on the reduction of surface $p \mathrm{CO}_{2}$. This implies that upwelling rate and nutrient utilization together determine $\mathrm{CO}_{2}$ outgassing. To accurately reconstruct these processes in the Namibia upwelling region, we apply different $\mathrm{CO}_{2}$-system proxies, such as the boron isotopic composition $\left(\delta^{11} \mathrm{~B}\right)$ in the foraminifera shell, the ratio of boron to calcium $(\mathrm{B} / \mathrm{Ca})$, and the carbon isotopic composition $\left(\delta^{13} \mathrm{C}\right)$ of alkenones. This multiproxy approach allows the independent reconstruction of parameters of the carbonate system and thus quantification of the complete inorganic carbon system. Along with these proxies for the $\mathrm{CO}_{2}$ system, the $\delta^{13} \mathrm{C}$ of planktic and benthic foraminiferal shells will be analyzed to evaluate efficiency of the carbon pump and its role in $\mathrm{CO}_{2}$ outgassing over the last $25 \mathrm{ka}$. 